\title{
Ethnic disparities of beverage consumption in infants and children $0-5$ years of age; National Health and Nutrition Examination Survey 2011 to 2014
}

Elieke Demmer ${ }^{1 *} \mathbb{D}$, Christopher J. Cifelli ${ }^{1}$, Jenny A. Houchins ${ }^{1}$ and Victor L. Fulgoni $\|^{2}$

\begin{abstract}
Background: Dietary patterns, including beverage consumption, that are developed during a child's first few years of life have been shown to impact dietary choices made later in life. Authoritative sources provide beverage recommendations for infants and children; however, it is unclear if these guidelines are followed and what, if any, the differences are among races/ethnicities. The objective of this study was to examine beverage consumption to recommendations among children 0-5 months, 6-11 months, 12-23 months, 2-3 years, and 4-5 years. Additionally, examine how these beverage patterns associate with nutrient intake and to determine if differences exist in beverage consumption among race/ethnic groups (Non-Hispanic White, Non-Hispanic Black, Hispanic, and Asian) in children aged $0-23$ months, 2-3 years, and $4-5$ years.
\end{abstract}

Methods: Data from the 2011-2014 National Health and Nutrition Examination Survey (NHANES) for children $0-5$ years were analyzed $(n=2445)$. Beverages were classified as follows; milk, 100\% juice, diet beverages, sugar sweetened beverages (SSB), and water.

Results: Our results show that regardless of race/ethnicity, dietary recommendation were not always followed. Prior to 6 months, 10\% of infants consumed any amount of 100\% juice; from 6 to 11 months, 17\% of young children were drinking any amount of milk. SSB consumption rapidly increased with age, whereas intake of milk and 100\% juice declined after 2 to 3 years of age. Non-Hispanic Black young children consumed the most 100\% juice from 2 to 3 years and up, exceeding recommended amounts, and throughout all age groups they consumed the least milk and most SSBs. The decreased intake of nutrient-rich beverages with age was associated with lower intakes of under-consumed nutrients of public health concern. By $4-5$ years, $32.7 \%$ and $93.8 \%$ of children were consuming $<$ EAR for calcium and vitamin D, respectively.

Conclusions: Dietary recommendations for both the introduction of beverages and amounts consumed were not consistently followed for American infants and children 0-5 years. Race/ethnic disparities exist in beverage consumption with Non-Hispanic Black children consuming the least amount of milk and most SSBs. Improving beverage consumption patterns could help improve overall diet quality which directly contributes to overall childhood health.

Keywords: Infants, Children, Beverage, Recommendations, Ethnic disparities, Milk, 100\% juice, Sugar sweetened beverage, Nutrient intake

\footnotetext{
*Correspondence: eliekedemmer@gmail.com

${ }^{1}$ National Dairy Council, 10255 West Higgins Road, Suite 900, Rosemont, IL 60018-5616, USA

Full list of author information is available at the end of the article
}

(c) The Author(s). 2018 Open Access This article is distributed under the terms of the Creative Commons Attribution 4.0 International License (http://creativecommons.org/licenses/by/4.0/), which permits unrestricted use, distribution, and reproduction in any medium, provided you give appropriate credit to the original author(s) and the source, provide a link to the Creative Commons license, and indicate if changes were made. The Creative Commons Public Domain Dedication waiver (http://creativecommons.org/publicdomain/zero/1.0/) applies to the data made available in this article, unless otherwise stated. 


\section{Background}

Infancy and early childhood are periods of rapid growth and development, which requires adequate consumption of essential macro- and micronutrients. Dietary patterns developed during these early life stages can form the basis for future food and beverage preferences [1, 2], thus potentially impacting early- and later-life development. Beverages provide a substantial amount of kilocalories (kcals) and nutrients to the diets of children [3-5]. While some beverages are nutrient rich, others can be a source of nutrients to limit, such as added sugar. For this reason, the U.S. Department of Agriculture (USDA) and Health and Human Services (HHS) have asked for additional information to better understand beverage patterns among infants and children, as the 2020-2025 Dietary Guidelines for American (DGA) will include recommendations for the $0-2$ years age range for the first time $[6,7]$.

Currently, the American Academy of Pediatrics (AAP) provides recommendations for the introduction of beverages to infants and children. Exclusive breastfeeding is recommended for approximately 6 months and continued breastfeeding for at least 12 months [8]. This recommendation is in part due to evidence suggesting that breastfeeding has a positive impact on the development of a child's later eating behavior $[9,10]$. The AAP also recommends that $100 \%$ juice not be introduced to the diet before 1 year of age and, once introduced, consumption should be limited to $4 \mathrm{oz}$ (oz) per day for children 1 to 3 years and 4-6 oz. per day for children 4 to 6 years [11]. These recently updated juice recommendations reflect the research showing that prolonged exposure of the teeth to the sugars in juice is a major contributing factor to dental caries, as well as the fact that fruit juices lack protein and fiber which can predispose children to inappropriate weight gain [11]. Cow's milk is not recommended for the first year of life as it provides inadequate iron, vitamin E, zinc, and essential fatty acids and excessive amounts of sodium, potassium, chloride, and protein for infants [12]. The introduction of plain whole milk is recommended at 1 year and the AAP suggests 16-24 oz. of milk per day [12]. According to experts, no restriction of fat or cholesterol is recommended for children younger than 2 years, as this is a period of rapid growth and neurologic development with high energy requirements, unless a concern for obesity or family history of cardiovascular disease exists [12]. The Institute of Medicine (IOM) has set Adequate Intakes (AI) for water consumption for $0-5$ yrs. While the water AI for infants $7-12$ mo of age is $0.8 \mathrm{l} /$ day, it should be noted that all beverages and moisture in foods is included in this AI [13]. See Table 1 for a summary of all beverage recommendations for children $0-5$ yrs. of age.

Starting at 2 years, the 2015-2020 DGA recommends low-fat or fat-free milk, in addition to $100 \%$ juice and water, as primary beverages of choice [3]. It should be noted that the DGA recommends no more than half of the fruit group be consumed as $100 \%$ juice [3]. The Academy of Nutrition and Dietetics (AND) does not recommend beverages with added sugars for infants and suggests that if toddlers consume sugar sweetened beverages (SSBs), they should be considered treats and potentially eliminated from the diet [14]. If SSB are consumed, overall amounts should be within overall kcal limits [3].

Several recent reports indicate that these recommendations for beverage intake in children are not consistently followed. In a 2004 to 2005 Oregon based population survey of nearly 2000 mothers, more than half (59.9\%) of the mothers reported that their 2 year-old child drank a SSB at least 1 day per week [15]. Similarly, among a sample of 1189 parents participating in the 2005-2007 Infant Feeding Practices Study II and who were followed up with when their child was 6 years old, a quarter $(25.9 \%)$ reported that their children consumed SSBs during infancy [16]. Additionally, these data showed that the prevalence of childhood obesity at 6 years was highest among children who either were introduced to SSBs before 6 months of age or who consumed SSBs more than 3 times per week during age 1012 months [16]. Additionally, research has shown that higher SSB consumption is associated with decreased milk consumption, which could impact the ability of children to meet nutrient recommendations [17]. These observed beverage consumption patterns among infants and children are of concern as early dietary choices have

Table 1 Beverage recommendations for children

\begin{tabular}{llllll}
\hline & $0-5$ months $^{1}$ & $6-11$ months $^{2}$ & $12-23$ months $^{3}$ & $2-3$ years & \\
\hline $100 \%$ Juice & 0 & 0 & $4 \mathrm{oz}$ & 4 oz & $4-5$ years $^{5}$ \\
Water $^{6}$ & 0 & 0.8 Liters/day & 1.3 Liters/day & 1.3 Liters/day & 1.7 Liters/day \\
Milk & 0 & 0 & $16-24$ oz. (whole milk) & 2 cups (low fat, fat free) & 2.5 cups (low fat, fat free) \\
Sweetened Beverages & 0 & 0 & Treats only, ideally eliminated & Within kcal limit & Within kcal limit \\
\hline
\end{tabular}

1) 0-5 months $100 \%$ Juice $(11,12,27)$, water $(12,27)$, milk $(12,27)$, sweetened beverages $(12,14,27) ; 2)$ 6-11 months $100 \%$ Juice (11), water (13), milk (12), sweetened beverages (14); 3) 12-23 months 100\% Juice (11), water (13), milk, (12), sweetened beverages (14); 4) 2-3 years 100\% Juice (11), water (13), milk (3), sweetened beverages (3); 5) 4-5 years 100\% Juice (11), water (13), milk (3), sweetened beverages (3); 6 ) The adequate intake (Al) is listed for children 6 months to 5 years as recommended by the IOM, these Al's include water from all beverages and moisture in foods 
been shown to influence diet choices made later in life and thus can influence diet quality and nutrient adequacy which are important modifiable risk factors for non-communicable diseases [18].

Few studies have researched beverage consumption in children by race/ethnicity, especially during the first 2 years of life. A trend analysis among children 2 to 11 years from 2003 to 2009 reported a decrease in consumption of 2 or more servings of $100 \%$ juice per day among Non-Hispanic White children and an increase among Hispanics [19]. Results from 2007 to 2010 National Health and Nutrition Examination Survey (NHANES) analysis showed that $100 \%$ fruit juice consumption was significantly higher among Non-Hispanic Black and Hispanic children compared to Non-Hispanic White children [20]. Marked differences among race/ethnic groups were reported for milk consumption for 2 to 18 -year-old children and adolescents based on 2001 to 2004 NHANES data. Only $15 \%$ of Non-Hispanic Black children met the recommended servings for milk compared to $42 \%$ of Non-Hispanic White children and $49 \%$ of Hispanic children [21].

Nutrient rich beverages provide a significant percentage of essential nutrients to the diet of infants and young children [22]. The purpose of this analysis was to examine beverage patterns among American infants and young children ( $0-5$ years); specifically, to determine the proportion of children who consume different beverage types across age groups, examine the impact of these beverage consumption patterns on nutrient adequacy for nutrients of public health concern, and determine if beverage recommendations are followed among varying age and race/ethnic groups.

\section{Methods}

\section{Subjects}

Using data from NHANES 2011-2014, we conducted separate analyses for various young age groups in the U.S. population (males and females combined; total $n=$ 2445). Age groups were chosen to align with beverage recommendations from authoritative sources: $0-5$ months $(n=233), 6-11$ months $(n=301), 12-23$ months $(n=$ $397), 2-3$ years, $(n=839)$ and $4-5$ years $(n=675)$. Analyses were also run to determine if there were any differences among race/ethnic groups; Non-Hispanic White $(n$ $=591)$, Non-Hispanic Black $(n=643)$, Hispanic $(n=833)$, Asians $(n=222)$, and other $(n=156)$. Due to smaller sample sizes for race/ethnic groups, within these race/ethnic analyses the following age breakdowns were used 023 months $(n=931), 2-3$ years, $(n=839)$ and $4-5$ years $(n=675)$ (Table 2). Subjects with other race/ethnicity designations were not studied as they were not representative of the national population. Only subjects with reliable 24-h recall interviews who met minimum criteria as
Table 2 Sample sizes by age and race/ethnicty

\begin{tabular}{|c|c|c|c|c|}
\hline \multirow[t]{2}{*}{ Ethnicity } & \multicolumn{4}{|l|}{ Age Group } \\
\hline & $0-23$ Months & 2-3 Years & 4-5 Years & All \\
\hline Hispanic & $328(39 \%)$ & $265(32 \%)$ & $240(29 \%)$ & 833 \\
\hline Non-Hispanic White & $250(42 \%)$ & 202 (34\%) & 139 (24\%) & 591 \\
\hline Non-Hispanic Black & $233(36 \%)$ & $242(38 \%)$ & $168(26 \%)$ & 643 \\
\hline Asian & $62(28 \%)$ & $80(36 \%)$ & $80(36 \%)$ & 222 \\
\hline Other & $58(37 \%)$ & $50(32 \%)$ & 48 (31\%) & 156 \\
\hline All & 931 (38\%) & 839 (34\%) & $675(28 \%)$ & 2,445 \\
\hline
\end{tabular}

established by the United States Department of Agriculture (USDA) were included in the analyses [22, 23]; additionally, given lack of quantification of intake, those consuming human milk were also excluded $(n=260)$.

\section{Beverage and nutrient intakes}

Day 1 24-h dietary recalls (provided by parents/caretakers) were used to assess intake of specific beverages on any given day using definitions in the USDA food category system used for NHANES [24]. The day 1 recall was collected via an in-person interview and used the validated Automated Multi Pass Method and is the best estimate of consumption on any given day. The beverage groups examined were as follows; 1) 100\% Juice: citrus, apple, other fruit, vegetable, baby juice. 2) Water: tap, bottled, flavored, carbonated, enhanced, fortified, baby water. 3) Milk: milk, flavored milk, milk shakes, dairy drinks, milk substitutes. 4) Diet Beverages: diet soft drinks, diet sport drinks, diet energy drinks, other diet drinks. 5) Sugar Sweetened Beverages: soft drinks, fruit drinks, sport drinks, energy drinks, nutritional beverages. 6) Coffee and Tea: coffee, tea. Data representing the percent of children who consumed each beverage (any amount), the amount of beverage consumed, and energy from beverages are presented as mean \pm standard error (SE) for each age group. For comparative purposes the percentage of kcals from each beverage was determined along with percent kcals from other foods. The intake of milk and flavored milk based on fat type using USDA defined categories were also determined (i.e., whole, reduced fat, low fat, and nonfat).

\section{Statistical analyses}

The distribution of usual intake including percentiles and percentages meeting cutoffs was estimated using version 2.1 of the National Cancer Institute (NCI) usual intake programs [25]. The estimates are generated with 2 days of dietary data (second day recall was gathered via the telephone 3-10 days after the in-person interview; this second day data are used to help define intraand inter-person variation) with day 1 dietary weights used in all stages of the estimation process. Balanced 
repeated replicates (BRR) were used which equal the smallest multiple of 4 that is greater than the number of NHANES strata in the input dataset for the usual intake. A non-response adjustment based on age, gender and race/ethnicity was made to BRR weights for each replication. The covariates used in the usual intake models were dietary recall number ( 1 or 2 ), and day of recall coded as weekday or weekend (Friday, Saturday, and Sunday). Nutrients reported included: calcium, iron, magnesium, phosphorus, potassium, zinc and vitamins A, C, and D. Race/ethnicity information came from NHANES demographic files based on responses during the in home questionnaire [26]. SAS 9.2 (SAS Institute, Cary, NC) was used with NHANES design aspects (primary sampling units and strata) and appropriate sampling weights to ensure estimates are nationally representative. Mean amounts, percentages and SEs were determined with "Proc Surveymeans" procedure and differences in means by age and or race/ethnicity were determined by $\mathrm{t}$-tests with $p<0.01$ as significant.

\section{Results}

\section{Beverage choices}

For the total sample of children, $20.5 \%$ of total kcals were from beverages evaluated $(289 \mathrm{kcal})$ and $79.5 \%$ of kcals were from food $(1100 \mathrm{kcal})$. The caloric contribution to the overall diet by beverage type were plain milk (10.7\%), 100\% juice (4.3\%), SSBs (3.4\%) and flavored milk (2.2\%).

Reported beverage consumption on any given day by age among infants and children are presented in Table 3. Regardless of race/ethnicity, over $10 \%$ of infants younger than 6 months reported consuming 100\% juice and more than $24 \%$ consumed small amounts of water despite recommendations to exclusively consume human milk, or in the absence of human milk, iron-fortified infant formula. The IOM recommends no supplementation of water, juice, nonhuman milk, or foods prior to 6 months of age [27]. For infants 6 to 11 months, over 17\% consumed milk and 5\% drank SSBs. Milk consumption was highest among 1 to 2 years where only $10 \%$ did not consume milk. Milk intake declined after the second year of life. More than $12 \%$ of 2 to 3 -year olds did not consume milk and this number increased to over $17 \%$ in 4 to 5 years. While milk consumption decreased with age, consumption of SSBs significantly increased with age. For children 12-23 months, nearly 31\% consumed SSBs, which significantly increased to $40 \%$ for children 2 to 3 years and to more than $51 \%$ for children 4 to 5 years.

Since milk recommendations vary by milk fat level as children get older, Table 4 presents the amount of milk consumed on any given day by type for each age group. Whole milk was the predominant type consumed by children 2 years and younger. For children 2 to 5 years reduced fat $(2 \%)$ milk was the predominant type consumed. The mean amount of milk consumed was lower than recommendations for all age groups.

The amounts of milk, 100\% juice and SSBs consumed on any given day by age and race/ethnicity are presented in Table 5. Milk consumption was highest among Non-Hispanic White children from 0 to 23 months, among Hispanic children from 2 to 3 years, and Asian children consumed the most milk from 4 to 5 years. Milk consumption was consistently the lowest among Non-Hispanic Black children after 2 years of age. Non-Hispanic Black children consumed the most 100\% juice during the first 3 years of life, while Asian children consumed significantly less $100 \%$ juice from 4 to 5 years than all other races/ethnicities. $100 \%$ juice consumption decreased after 3 years across all the race/ethnic groups. Non-Hispanic Black children consumed the highest amount of SSBs among all age groups. In comparison, Asian children consumed the least amount of SSBs during the first 5 years of life.

The kcal contribution of the reported beverage choices on any given day is presented in Table 6. Regardless of

Table 3 Percent of children consuming different beverage types on a given day, NHANES 2011-2014

\begin{tabular}{|c|c|c|c|c|c|}
\hline & $\begin{array}{l}0-5 \text { months } \\
(n=233)\end{array}$ & $\begin{array}{l}6-11 \text { months } \\
(n=301)\end{array}$ & $\begin{array}{l}12-23 \text { months } \\
(n=397)\end{array}$ & $\begin{array}{l}2-3 \text { years } \\
(n=839)\end{array}$ & $\begin{array}{l}4-5 \text { years } \\
(n=675)\end{array}$ \\
\hline & Mean \pm SEM & Mean \pm SEM & Mean \pm SEM & Mean \pm SEM & Mean \pm SEM \\
\hline $100 \%$ Juice $^{1}$ & $10.13^{\mathrm{a}} \pm 1.96$ & $38.78^{b} \pm 3.68$ & $58.23^{\mathrm{c}} \pm 3.48$ & $53.97^{c} \pm 2.37$ & $49.05^{\complement} \pm 3.26$ \\
\hline Water $^{2}$ & $24.69^{\mathrm{a}} \pm 4.45$ & $61.88^{b} \pm 2.92$ & $77.46^{\mathrm{C}} \pm 2.83$ & $82.18^{\mathrm{C}} \pm 1.55$ & $79.23^{\mathrm{C}} \pm 2.30$ \\
\hline Milk ${ }^{3}$ & $0.73^{\mathrm{a}} \pm 0.54$ & $17.47^{b} \pm 3.09$ & $90.86^{\complement} \pm 1.97$ & $87.49^{c} \pm 1.47$ & $82.74^{c} \pm 2.13$ \\
\hline Diet Beverages ${ }^{4}$ & $0^{a} \pm 0$ & $0^{\mathrm{a}} \pm 0$ & $2.11^{\mathrm{ab}} \pm 1.08$ & $3.51^{b} \pm 0.93$ & $5.07^{b} \pm 0.79$ \\
\hline Sweetened Beverages ${ }^{5}$ & $0.66^{a} \pm 0.52$ & $5.05^{b} \pm 1.00$ & $30.97^{c} \pm 3.73$ & $40.19^{c d} \pm 3.04$ & $51.32^{d} \pm 3.83$ \\
\hline Coffee and Tea ${ }^{6}$ & $0^{a} \pm 0$ & $0.55^{\mathrm{a}} \pm 0.56$ & $7.25^{b} \pm 1.70$ & $8.94^{\mathrm{b}} \pm 1.41$ & $8.37^{b} \pm 1.35$ \\
\hline
\end{tabular}

Data based on Day 1 dietary recalls

SEM, Standard Error of the Mean. 1) 100\% Juice includes: citrus, apple, other fruit, vegetable, baby juice. 2) Water includes: tap, bottled, flavored, carbonated, enhanced, fortified, baby water. 3) Milk includes: milk, flavored milk, milk shakes, dairy drinks, milk substitutes. 4) Diet Beverages includes: diet soft drinks, diet sport drinks, diet energy drinks, other diet drinks. 5) Sugar Sweetened Beverages includes: soft drinks, fruit drinks, sport drinks, energy drinks, nutritional beverages. 6) Coffee and Tea includes: coffee, tea. ${ }^{a}, b, c, d$ Means sharing the same superscripts are not significantly different across ages, $p<0.01$ 
Table 4 Amount of milk consumed on a given day by milk-type and age, NHANES 2011-2014

\begin{tabular}{|c|c|c|c|c|c|}
\hline & $\begin{array}{l}0-5 \text { months } \\
(n=233)\end{array}$ & $\begin{array}{l}6-11 \text { months } \\
(n=301)\end{array}$ & $\begin{array}{l}12-23 \text { months } \\
(n=397)\end{array}$ & $\begin{array}{l}2-3 \text { years } \\
(n=839)\end{array}$ & $\begin{array}{l}4-5 \text { years } \\
(n=675)\end{array}$ \\
\hline & Grams $^{1} \pm$ SEM & Grams $^{1} \pm$ SEM & Grams $^{1} \pm$ SEM & Grams $^{1} \pm$ SEM & Grams $^{1} \pm$ SEM \\
\hline Milk, whole & $3.15^{\mathrm{a}} \pm 3.12$ & $53.90^{\mathrm{b}} \pm 11.80$ & $345.60^{c} \pm 26.68$ & $99.12^{d} \pm 12.66$ & $57.16^{b} \pm 12.68$ \\
\hline Milk, reduced fat & $0.11^{a} \pm 0.11$ & $11.79^{b} \pm 3.32$ & $90.49^{c} \pm 13.00$ & $150.07^{d} \pm 12.46$ & $105.44^{c} \pm 8.19$ \\
\hline Milk, lowfat & $0^{\mathrm{a}} \pm 0$ & $3.56^{\mathrm{ab}} \pm 1.98$ & $15.35^{b c} \pm 5.14$ & $34.12^{c} \pm 6.51$ & $45.46^{\mathrm{bc}} \pm 15.51$ \\
\hline Milk, nonfat & $0^{a} \pm 0$ & $0.02^{\mathrm{a}} \pm 0.02$ & $2.25^{\mathrm{ab}} \pm 1.28$ & $19.58^{b} \pm 6.98$ & $17.98^{b} \pm 5.74$ \\
\hline Flavored Milk, whole & $0^{a} \pm 0$ & $0.34^{a} \pm 0.34$ & $8.23^{\mathrm{ab}} \pm 4.08$ & $10.79^{b} \pm 2.77$ & $20.85^{b} \pm 5.88$ \\
\hline Flavored Milk, reduced fat & $0^{a} \pm 0$ & $1.29^{\mathrm{a}} \pm 1.23$ & $1.07^{\mathrm{a}} \pm 0.76$ & $31.36^{\mathrm{b}} \pm 7.71$ & $28.89^{b} \pm 5.22$ \\
\hline Flavored Milk, lowfat & $0^{a} \pm 0$ & $0^{a} \pm 0$ & $0^{\mathrm{a}} \pm 0$ & $11.96^{\mathrm{b}} \pm 3.06$ & $8.53^{b} \pm 2.49$ \\
\hline Flavored Milk, nonfat & $0^{\mathrm{a}} \pm 0$ & $0^{\mathrm{a}} \pm 0$ & $0^{a} \pm 0$ & $4.97^{b} \pm 1.60$ & $8.69^{b} \pm 2.66$ \\
\hline Dairy Drinks and Substitutes & $0^{a} \pm 0$ & $5.35^{\mathrm{ab}} \pm 5.14$ & $22.22^{b} \pm 6.44$ & $13.87^{\mathrm{b}} \pm 3.32$ & $11.22^{b} \pm 3.72$ \\
\hline
\end{tabular}

Data based on Day 1 dietary recalls

SEM Standard Error of the Mean. 1). One cup of milk is equivalent to $244 \mathrm{~g}$. ${ }^{\mathrm{a}, \mathrm{b}, \mathrm{c}, \mathrm{d}}$ Means sharing the same superscripts are not significantly different across ages, $p$ $<0.01$. Dairy drinks and substitutes includes milk substitutes, milk shakes, and other dairy drinks

race/ethnicity, milk and $100 \%$ juice contributed the most kcals for children across most age groups. The contribution of kcals from SSBs significantly increased with age. By 4 to 5 years, SSBs contributed 75 kcals to daily intake compared to $59 \mathrm{kcals}$ from $100 \%$ juice.

\section{Nutrient intakes}

Table 7 shows the percent of children below the Estimated Average Requirement (EAR) or above the AI for under-consumed nutrients that pose a public health concern by age. Over $90 \%$ of all children $2-3$ and $4-$ 5 years of age consumed less than the EAR for vitamin D. From 1 to 5 years our data showed the percent of children who consumed calcium amounts below the EAR consistently increased. Nearly $33 \%$ of children 4 to 5 years had calcium intakes below the EAR. Like calcium and vitamin $\mathrm{D}$, potassium intake also decreased with age, particularly after the first year. Less than $1 \%$ of children had potassium intakes above the AI by 4 to 5 years of age.

Table 5 Amount of Total Milk, 100\% Juice, and Sugar Sweetened Beverages consumed on a given day by age and race/ethnicity, NHANES 2011-2014

\begin{tabular}{|c|c|c|c|}
\hline & 0-23 Months & 2-3 Years & $4-5$ Years \\
\hline & Mean \pm SEM & Mean \pm SEM & Mean \pm SEM \\
\hline \multicolumn{4}{|l|}{ Milk' (cups eq.) } \\
\hline Non-Hispanic White $(n=591)$ & $1.31^{a} \pm 0.12$ & $1.50^{\mathrm{ab}} \pm 0.10$ & $1.30^{\mathrm{ab}} \pm 0.18$ \\
\hline Non-Hispanic Black $(n=643)$ & $0.83^{b} \pm 0.08$ & $1.14^{a} \pm 0.12$ & $0.83^{\mathrm{a}} \pm 0.10$ \\
\hline Hispanic $(n=833)$ & $1.21^{\mathrm{a}} \pm 0.09$ & $1.65^{b} \pm 0.10$ & $1.33^{b} \pm 0.09$ \\
\hline Asian $(n=222)$ & $1.06^{\mathrm{ab}} \pm 0.24$ & $1.61^{\mathrm{ab}} \pm 0.34$ & $1.43^{\mathrm{b}} \pm 0.14$ \\
\hline \multicolumn{4}{|l|}{ 100\% Juice ${ }^{2}$ (cups eq.) } \\
\hline Non-Hispanic White & $0.35 \pm 0.06$ & $0.57 \pm 0.08$ & $0.47^{b} \pm 0.05$ \\
\hline Non-Hispanic Black & $0.44 \pm 0.07$ & $0.80 \pm 0.11$ & $0.44^{\mathrm{ab}} \pm 0.06$ \\
\hline Hispanic & $0.41 \pm 0.04$ & $0.51 \pm 0.06$ & $0.47^{b} \pm 0.06$ \\
\hline Asian & $0.31 \pm 0.07$ & $0.62 \pm 0.09$ & $0.21^{a} \pm 0.07$ \\
\hline \multicolumn{4}{|l|}{ Sugar Sweetened Beverages ${ }^{3}$ (oz) } \\
\hline Non-Hispanic White & $1.37^{\mathrm{ab}} \pm 0.38$ & $3.76^{\mathrm{ab}} \pm 0.57$ & $5.74^{b} \pm 0.92$ \\
\hline Non-Hispanic Black & $3.54^{b} \pm 0.82$ & $5.63^{b} \pm 0.70$ & $9.12^{\mathrm{b}} \pm 1.01$ \\
\hline Hispanic & $2.28^{\mathrm{ab}} \pm 0.53$ & $5.21^{\mathrm{ab}} \pm 0.76$ & $6.79^{b} \pm 0.95$ \\
\hline Asian & $0.63^{\mathrm{a}} \pm 0.42$ & $2.82^{\mathrm{a}} \pm 0.75$ & $2.19^{a} \pm 0.65$ \\
\hline
\end{tabular}

Data based on Day 1 dietary recalls

SEM Standard Error of the Mean. 1) Milk includes: milk, flavored milk, milk shakes, dairy drinks, milk substitutes. 2) 100\% Juice includes: citrus, apple, other fruit, vegetable, baby juice. 3) Sugar Sweetened Beverages includes: soft drinks, fruit drinks, sport drinks, energy drinks, nutritional beverages. ${ }^{\mathrm{a}, \mathrm{b}}$ Means sharing the same superscripts are not significantly different by race/ethnicity within age groups, $p<0.01$ 
Table 6 Daily kilocalorie (kcal) contribution of beverage choice on a given day by age, NHANES 2011-2014

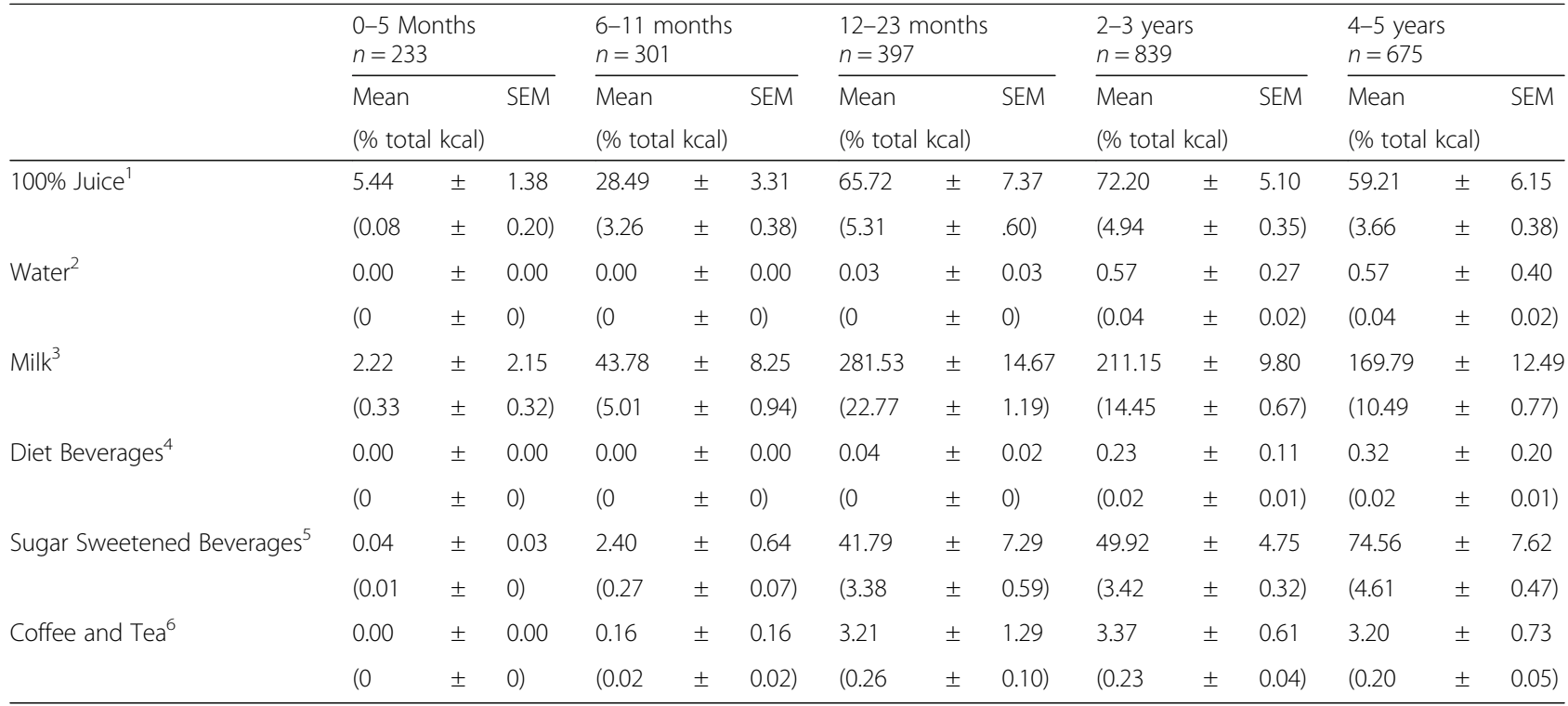

Data based on Day 1 dietary recalls

SEM, Standard Error of the Mean. 1) $100 \%$ Juice includes: citrus, apple, other fruit, vegetable, baby juice. 2) Water includes: tap, bottled, flavored, carbonated, enhanced, fortified, baby water. 3) Milk includes: milk, flavored milk, milk shakes, dairy drinks, milk substitutes. 4) Diet Beverages includes: diet soft drinks, diet sport drinks, diet energy drinks, other diet beverages. 5) Sugar Sweetened Beverages includes: soft drinks, fruit drinks, sport drinks, energy drinks, nutritional beverages. 6) Coffee and Tea includes: coffee, tea

\section{Discussion}

Authoritative sources have put forward dietary recommendations, including for beverages, to help populations maintain health and reduce the risk for disease $[3,12,14]$. Traditionally the DGAs have only provided dietary recommendations for Americans ages 2 years and older; however, the 2020-2025 DGAs will include recommendations for infants and children from birth to 2 years [7]. As such, the USDA and HHS have asked for additional data on dietary and beverage patterns for this young age group [6]. Our study utilized NHANES data to determine if beverage recommendations were followed for American children during their first 5 years of life. Our results indicate that beverage recommendations were generally not followed across early childhood, despite providing significant amounts of kcals to the diet.

From birth to 6 months the AAP recommends exclusive breastfeeding or formula feeding [12], which the IOM explains as no supplementation of water, juice,

Table 7 Percent of children below the Estimated Average Requirement (EAR) or above the Adequate Intake (AI) by age, NHANES 2011-2014

\begin{tabular}{|c|c|c|c|c|c|c|c|c|c|c|c|c|}
\hline \multirow[b]{3}{*}{ Calcium (mg) } & \multicolumn{4}{|c|}{$\begin{array}{l}12-23 \text { months } \\
(n=397)\end{array}$} & \multicolumn{4}{|c|}{$\begin{array}{l}2-3 \text { years } \\
(n=839)\end{array}$} & \multicolumn{4}{|c|}{$\begin{array}{l}4-5 \text { years } \\
(n=675) \\
\end{array}$} \\
\hline & $\%>\mathrm{Al}$ & $\%<$ EAR & & SEM & $\%>\mathrm{Al}$ & $\%<$ EAR & & SEM & $\%>\mathrm{Al}$ & $\%<$ EAR & & SEM \\
\hline & & $2.22^{\mathrm{a}}$ & \pm & 0.75 & & $2.90^{\mathrm{a}}$ & \pm & 0.76 & & $32.74^{\mathrm{b}}$ & \pm & 3.13 \\
\hline Iron (mg) & & $1.67^{\mathrm{a}}$ & \pm & 0.58 & & $0.75^{\mathrm{a}}$ & \pm & 0.19 & & $2.37^{\mathrm{ab}}$ & \pm & 0.45 \\
\hline Magnesium (mg) & & $0.02^{\mathrm{a}}$ & \pm & 0.03 & & $0.004^{a}$ & \pm & 0.01 & & $1.15^{\mathrm{b}}$ & \pm & 0.36 \\
\hline Phosphorus (mg) & & 0.03 & \pm & 0.05 & & 0.01 & \pm & 0.01 & & 0.02 & \pm & 0.02 \\
\hline Vitamin A, (mcg) & & $0.69^{\mathrm{a}}$ & \pm & 0.34 & & $0.63^{\mathrm{a}}$ & \pm & 0.28 & & $3.88^{\mathrm{b}}$ & \pm & 1.06 \\
\hline Vitamin C (mg) & & 0.39 & \pm & 0.21 & & 0.16 & \pm & 0.09 & & 1.96 & \pm & 0.73 \\
\hline Vitamin D (mcg) & & $76.53^{a}$ & \pm & 3.51 & & $90.01^{b}$ & \pm & 1.96 & & $93.78^{b}$ & \pm & 1.67 \\
\hline Zinc (mg) & & 0.02 & \pm & 0.02 & & 0.00 & \pm & 0.02 & & 0.45 & \pm & 0.32 \\
\hline Potassium (mg) & 1.67 & & \pm & 0.70 & 2.82 & & \pm & 0.68 & 0.18 & & \pm & 0.12 \\
\hline
\end{tabular}

Data from usual intake using the National Cancer Institute method with two days of dietary recalls. Nutrients from breast milk are not be included in these analyses

EAR, Estimated Average Requirement; Al, Adequate Intake; SEM, Standard Error of the Mean. ${ }^{\mathrm{a}, \mathrm{b}}$ Means sharing the same superscripts for EAR percentages after 1 year are not significantly different across ages, $p<0.01$ 
nonhuman milk, or foods [27]. However, our analysis showed that on any given day nearly $12 \%$ of infants under 6 months consumed 100\% juice and over $21 \%$ consumed water. Early introduction of water to infants less than 6 months may be of concern since it can displace consumption of nutrient-rich human milk or infant formula.

\section{Milk}

Our results show that milk was introduced earlier than recommended. On any given day, nearly $22 \%$ of children 6 to 11 months already consumed cow's milk in quantities ranging from 0.2 to 0.4 cups per day. The mean amount of milk consumed on any given day decreased after 2 years for each of the race/ethnic groups analyzed. All groups consumed less than 2 cups of milk per day among children 2 to 5 years, with Non-Hispanic Black children consuming the least. A decrease in milk consumption as children age has been reported previously in population, survey, and clinical trial studies [22, 28, 29]. Differences among race/ethnic groups have been reported for milk consumption among children and adolescents ( $2-18$ years) based on 2001-2004 NHANES data [21]. These results, along with our current data, highlight that across all ages a very small proportion of Non-Hispanic Black children consume sufficient amounts of milk. Cross-sectional data indicate that diet quality can be related to socioeconomic status [30]; however, factors such as income and education level were not included in in this study. Additionally, NHANES 2013-2014 data show that total dairy and milk consumption do not vary by family income [31]. Differences in milk consumption might be explained by genetic predisposition of Non-Hispanic Blacks toward lactose intolerance, as well as cultural beliefs and perceptions about consumption of dairy products [32,33]. Previous research indicates that approximately $20 \%$ of Hispanic, Asian, and Non-Hispanic Black children younger than 5 years of age have evidence of lactase deficiency and lactose malabsorption [34]. Nevertheless, the AAP encourages children with lactose intolerance to keep dairy foods in the diet to help meet nutrient needs [35]. Thus, personalized management strategies can help, such as consuming small amounts of dairy foods at a time, consuming milk with meals, and opting for lactose-free or reduced-lactose cow's milk to help ensure children meet nutrient recommendations [36]. Our results show that the Asian population, who is believed to have a high prevalence of lactase deficiency as well [35], has seemingly overcome these barriers as statistically Asian children consumed the same amount of milk as Non-Hispanic White and Hispanic children from 2 to 5 years.

\section{$100 \%$ juice}

Our results show that $100 \%$ juice consumption decreased after 2 to 3 years, similar to milk consumption.
The DGA recognizes 100\% juice as a beverage that can contribute beneficial nutrients to the diet, but states that juice should not provide more than half of the recommended fruit intake [3]. One-hundred percent juice can provide substantial amounts of vitamin $\mathrm{C}$ and potassium, but lacks the dietary fiber found in whole fruits or vegetables [20]. Thus, the AAP recommends that juice should not be introduced into the diet of infants before 12 months of age, and the intake of juice should be limited to 4 oz. or 4-6 oz. per day for children 1 to 3 years and 4 to 6 years, respectively [11]. Based on these recommendations, our results indicate that on any given day, children consumed $100 \%$ juice too early (over $10 \%$ of infants $0-5$ months and nearly $40 \%$ of $6-11$ month old infants) and that Non-Hispanic Black children consumed the most $100 \%$ juice under 2 years of age. Non-Hispanic White, Non-Hispanic Black, Hispanic, and Asian children 2 to 3 years all consumed amounts of $100 \%$ juice that exceeded the AAP recommendations [11]. Higher $100 \%$ juice consumption for Non-Hispanic Black children has been reported previously [20]. Experts caution that excessive juice consumption may be associated with malnutrition, tooth decay, excessive weight gain, or gastrointestinal discomfort [11, 37-39].

\section{Sugar sweetened beverages}

SSB consumption steadily increased over time, consistent with prior research [29]. Regardless of race/ethnicity, we found an increase in consumption of SSBs as children got older and by 4 to 5 years, on any given day, over $51 \%$ of all children consumed SSBs. Increased consumption of SSBs by children is of concern due to their contribution to empty kcals and added sugar intake as well as displacement of more nutrient-rich beverages such as milk and $100 \%$ juice in the diet. Prior research showed increased consumption of SSBs in children was associated with an overall decrease in children's diet quality [17], an increase in childhood obesity [40], and increased risk for development of non-communicable diseases [18]. A recent scientific statement by the American Heart Association indicates that there is strong evidence that added sugar intake among children is associated with increased cardiovascular disease risk through increased energy intake, increased adiposity, and dyslipidemia. It was also recognized that when added sugars are consumed within energy limits, it is better if the sugars are consumed as part of nutrient-rich foods [18].

Consumption of SSB in this sample varied by race/ethnicity. Non-Hispanic Black children consumed the most SSBs during 0-23 months. During these first 2 years of life, Non-Hispanic Black children consumed nearly 2, 3, and 6 times more SSB than Hispanic, Non-Hispanic White, and Asian children, respectively. These results 
align with previously reported data [15, 41]. Garnett et al. surveyed parents on their child's beverage intake and found that Non-Hispanic Black children had the highest consumption of SSBs for all age groups. Moreover, Hispanic and Non-Hispanic Black mothers were more likely to report that their 2 yr. old children consumed a SSB at least once a week [15].

\section{Nutrients}

After 1 year, milk provided the most kcals of the beverages examined. This is appropriate as milk a nutrient rich food providing essential nutrients associated with proper growth [12], and its consumption has been associated with improved diet quality and bone health among children [42]. Milk is the number one food source of nine essential nutrients for children; protein, calcium, potassium, phosphorus, vitamins A, D, B12, riboflavin and niacin as niacin equivalents [5]. Among beverages consumed by American infants and children 0 to 5 years of age, our results show milk provided the largest nutrient contribution.

Non-Hispanic Black children consumed the least amounts of calcium and vitamin D from 1 to 5 years. Over $25 \%$ and $95 \%$ of Non-Hispanic Black children 15 years of age had inadequate intakes of calcium and vitamin D, respectively, as compared to 8.2 and $83.2 \%$ of Hispanics and 12.9 and $88.5 \%$ for Non-Hispanic White children (data not shown). Non-Hispanic Black children were the only race/ethnic group who consumed more SSBs than milk at 4 to 5 years of age. Regardless of race/ ethnicity, our data showed that the decreased consumption of nutrient-rich beverages, such as milk, as children got older was reflected in decreased intakes of the nutrients of public health concern. For children 4 to 5 years, nearly $94 \%$ had vitamin D intakes below the EAR, over $32 \%$ had calcium intakes below the EAR and less than $1 \%$ had potassium intakes above the AI. These low intakes for the under-consumed nutrients of public health concern among young American children are alarming as they are necessary for normal growth and development [36].

\section{Strengths and limitations}

One of the strengths of this study was the use of a sample representative of the $\mathrm{U}$. S population. A second strength was the inclusion of infants and children 0 to 24 months age group as many previous reports have focused only on children $2+$ years. Finally, we utilized the National Cancer Institute method for estimating usual intake to estimate percentage of the population meeting or below dietary recommendations. This study was limited by the fact that we were not able to analyze race/ethnic data in smaller age sub-groups due to the small sample sizes among young infants (0-12 months).
Additionally, due to the fact that NHANES data dietary information may be subject to over- or under-reporting and the accuracy of parents/caregivers reporting of their children's food intake is unknown.

\section{Conclusions}

Beverage consumption among American infants and children 0 to 5 years, as reported in NHANES 2011 to 2014, did not consistently follow recommendations from authoritative sources. Consumption of milk and 100\% juice decreased with age, particularly after 2 years, while consumption of SSBs steadily increased. Simultaneously, as children got older they had lower intakes of under-consumed nutrients of public health concern; calcium, vitamin D and potassium. Differences in beverage intakes exists when comparing various race/ethnic groups. Non-Hispanic Black children consumed the most 100\% juice from 2 to 3 years, exceeding recommended amounts, and throughout all age groups they consumed the least milk and most SSBs. These results highlight that improving beverage consumption patterns, particularly for Non-Hispanic Black children, could help improve overall diet quality that can reduce risk for obesity and other diet-related chronic diseases.

\section{Abbreviations \\ AAP: American Academy of Pediatrics; Al: Adequate Intake; AND: Academy of Nutrition and Dietetics; BBR: Balanced repeated replicates; DGA: Dietary Guidelines for Americans; EAR: Estimated Average Requirement; HHS: Health and Human Services; IOM: Institute of Medicine; kcals: Kilocalories; $\mathrm{NCl}$ : National Cancer Institute; NHANES: National Health and Nutrition Examination Survey; oz: Ounces; SE: Standard error; SSB: Sugar sweetened beverages; USDA: United States Department of Agriculture}

\section{Acknowledgements}

The study and the writing of the manuscript were supported by National Dairy Council. The Authors would like to thank Carla McGill, PhD, RD,

Principle at Healthy Science Communications for assistance with manuscript preparation.

\section{Funding}

National Dairy Council/Dairy Management Inc.

\section{Availability of data and materials}

The datasets analyzed during the current study are available in the Center for Disease Control and Prevention repository; National Health and Nutrition Examination Survey (2011-2012 and 2013-2014).

\section{Authors' contributions}

The authors' responsibilities were as follows- ED/CJC/JHNLF: project conception, designed research, developed overall research plan, determined content for manuscript and collaborated on the writing; VLF: analyzed data and performed statistical analysis; All authors read and approved the final manuscript.

\section{Ethics approval and consent to participate}

The data used for this manuscript was from the National Health and Nutrition Examination Survey (NHANES) 2011-2014; Data collection for NHANES was approved by the NCHS Research Ethics Review Board. Analysis of de-identified data from the survey is exempt from the federal regulations for the protection of human research participants. Analysis of restricted data through the NCHS Research Data Center is also approved by the NCHS ERB. 


\section{Consent for publication}

Not applicable.

\section{Competing interests}

ED, CJC, and JAH are employees of National Dairy Council/Dairy

Management Inc., Rosemont, Illinois, USA. VLF as Senior Vice President of Nutrition Impact, LLC performs consulting and database analyses for various food and beverage companies and related entities.

\section{Publisher's Note}

Springer Nature remains neutral with regard to jurisdictional claims in published maps and institutional affiliations.

\section{Author details}

'National Dairy Council, 10255 West Higgins Road, Suite 900, Rosemont, IL 60018-5616, USA. ${ }^{2}$ Nutrition Impact, LLC, Battle Creek, MI 49014, USA.

Received: 17 November 2017 Accepted: 9 August 2018

Published online: 22 August 2018

\section{References}

1. Birch L, Arbor A, Savage JS, Ventura A. Influences on the development of Children's eating Behaviours: from infancy to adolescence. Can J Diet Pr Res. 2009;68:1-11.

2. Savage JS, Fisher JO, Birch LL. Parental influence on eating behavior. J Law Med Ethics. 2008:35:22-34

3. U.S. Department of Health and Human Services and U.S. Department of Agriculture. Dietary Guidelines for Americans. 2015-2020.

4. Popkin BM. Patterns of beverage use across the lifecycle. Physiol Behav. 2010;100:4-9.

5. Keast D, Fulgoni $\vee$ 3rd, Nicklas T, O'Neil CE. Food sources of energy and nutrients among children in the United States: National Health and Nutrition Examination Survey 2003-2006. Nutrients. 2013;5:283-301.

6. Federal Register. Dietary Guidelines for Americans: Request for Comments on Topics and Questions. National Archives. USA. 2018;83(40).

7. Agricultural Act of 2014. H.R.2642-113th Congress. 2014.

8. Moretti M. Breastfeeding and the use of antidepressants. J Popul Ther Clin Pharmacol. 2012;19:e387-90.

9. Kramer MS. Do breast-feeding and delayed introduction of solid foods protect against subsequent obesity? J Pediatr. 1981;98:883-7.

10. Owen CG, Martin RM, Whincup PH, Smith GD, Cook DG. Effect of infant feeding on the risk of obesity across the life course: a quantitative review of published evidence. Pediatrics. 2005;115:1367-77. https://doi.org/10.1542/ peds.2004-1176

11. Heyman MB, Abrams SA. Fruit juice in infants, children, and adolescents: current recommendations. Pediatrics. 2017;139:e20170967.

12. American Academy of Pediatrics Committee on Nutrition. In: Kleinmen, RE, Greer, FR, eds. Pediatric Nutrition. 7th ed. Elk Grove Village, IL: American Academy of Pediatrics; 2014.

13. The National Academies. Dietary Reference Intakes for Water, Potassium, Sodium, Chloride, and Sulfate. 2004. https://www.nap.edu/read/10925/ chapter/1. Accessed Oct 2017.

14. Academy of Nutrition and Dietetics. Pediatric Nutrition Care Manual. http:// www.nutritioncaremanual.org. Accessed Oct 2017.

15. Garnett BR, Rosenberg KD, Morris DS. Consumption of soda and other sugar-sweetened beverages by 2-year-olds: findings from a populationbased survey. Public Health Nutr. 2013;16:1760-7.

16. Pan L, Li R, Park S, Galuska DA, Sherry B, Freedman DS. A longitudinal analysis of sugar-sweetened beverage intake in infancy and obesity at 6 years. World Rev Nutr Diet. 2016;114:34-5.

17. Marshall TA, Eichenberger Gilmore JM, Broffitt B, Stumbo PJ, Levy SM. Diet quality in young children is influenced by beverage consumption. J Am Coll Nutr. 2005;24:65-75.

18. Vos MB, Kaar JL, Welsh JA, van Horn LV, Feig DI, Anderson CAM, et al. Added sugars and cardiovascular disease risk in children: a scientific statement from the American Heart Association. Circulation. 2017;135(19): e1017-e1034.

19. Beck AL, Patel A, Madsen K. Trends in sugar-sweetened beverage and 100\% fruit juice consumption among California children. Acad Pediatr. 2013;13: 364-70.
20. Drewnowski A, Rehm CD. Socioeconomic gradient in consumption of whole fruit and 100\% fruit juice among US children and adults. Nutr J. 2015; 14:1-9.

21. Kirkpatrick SI, Dodd KW, Reedy J, Krebs-Smith SM. Income and race/ethnicity are associated with adherence to food-based dietary guidance among US adults and children. J Acad Nutr Diet. 2012;112:624-35.

22. Fulgoni VL, Quann EE. National trends in beverage consumption in children from birth to 5 years: analysis of NHANES across three decades. Nutr J. 2012; 11:92.

23. Centers for Disease Control and Prevention. National Health and Nutrition Examination Survey (NHANES). Dietary Interview - Total Nutrient Intakes, First Day. 2016. https://wwwn.cdc.gov/Nchs/Nhanes/2013-2014/DR1TOT_H. htm.

24. U.S. Department of Agriculture, Agricultural Research Service. What We Eat in America Food Categories 2011-2012. https://www.ars.usda.gov/ ARSUserFiles/80400530/pdf/1112/food_category_list.pdf. Accessed Oct 2017.

25. National Cancer Institute. Usual Dietary Intakes: SAS Macros for Analysis of a Single Dietary Component. USA. https://epi.grants.cancer.gov/diet/ usualintakes/macros_single.html. Accessed Oct 2017.

26. CDC/National Center for Health Statistics. About the National Health and Nutrition Examination Survey. https://www.cdc.gov/nchs/nhanes/about nhanes.htm. Accessed Oct 2017.

27. Institute of Medicine. Nutrition during lactation. Washington, D.C.: National Academies Press; 1991

28. Wang YC, Bleich SN, Gortmaker SL. Increasing caloric contribution from sugar-sweetened beverages and 100\% fruit juices among US children and adolescents, 1988-2004. Pediatrics. 2008;121:e1604-14.

29. Keller KL, Ph D, Kirzner J, Pietrobelli A, Faith MS. Increased sweetened beverage intake is associated with reduced milk and calcium intake in 3- to 7-yr old children at multi-item laboratory lunches. J Am Diet Assoc. 2010; 109:497-501.

30. Darmon N, Drewnowski A. Does social class predict diet quality? Am J Clin Nutr. 2008:87:1107-17.

31. Centers for Disease Control and Prevention (CDC). National Center for Health Statistics (NCHS). National Health and Nutrition Examination Survey Data. Hyattsville, MD: U.S. Department of Health and Human Services, Centers for Disease Control and Prevention; 2013-2014.

32. National Medical Association. Lactose intolerance and African Americans: implications for the consumption of appropriate intake levels of key nutrients. J Natl Med Assoc. 2009;101:S5-23.

33. Bailey RK, Fileti CP, Keith J, Price W, Allison-ottey SD. Lactose intolerance and health disparities among African Americans and Hispanic Americans: an updated consensus statement. J Natl Med Assoc. 2013;105:112-27. https:// doi.org/10.1016/S0027-9684(15)30113-9.

34. Woteki CE, Weser $\mathrm{E}$, Young EA. Lactose malabsorption in Mexican-American children. Am J Clin Nutr. 1976:29:19-24.

35. Heyman MB, others. Lactose intolerance in infants, children, and adolescents. Pediatrics. 2006;118:1279-86.

36. Suchy FJ, Brannon PM, Carpenter TO, Fernandez JR, Gilsanz V, Gould JB, et al. National Institutes of Health consensus development conference: lactose intolerance and health. Ann Intern Med. 2010;152:792.

37. AAP. Committee on Nutrition The Use and Misuse of Fruit Juice in Pediatrics. Pediatrics. 2001;107:1210-3.

38. Frantsve-Hawley J, Bader J, Welsh J, Wright J. A systematic review of the association between consumption of sugar-containing beverages and excess weight gain among children under age 12. J Public Heal Dent. 2017; 77(Supplement 1):S43-66.

39. Sonneville K, Long M, Rifas-Shiman S, Kleinman K, Gillman M, Taveras E. Juice and water intake in infancy and later beverage intake and adiposity: could juice be a gateway drink? Obesity. 2015;23:170-6.

40. Dubois L, Farmer A, Girard M, Peterson K. Regular sugar-sweetened beverage consumption between meals increases risk of overweight among preschool-aged children. J Am Diet Assoc. 2007;107:924-34.

41. Han E, Powell L. Consupmtion patterns of sugar sweetened beverages in the united state. J Acad Nutr Diet. 2014;113:43-53.

42. Lee WT, Leung SS, Lui SS, Lau J. Relationship between long-term calcium intake and bone mineral content of children aged from birth to 5 years. $\mathrm{Br}$ Nutr. 1993;70:235-48. 